ease activity/duration, health status, physical activity, fatigue and depression (table 2)

Conclusion: Women with SSc reported significantly impaired sexual func tion, sexual quality of life and pelvic floor function than age-matched $\mathrm{HC}$ Worse scores in SSc were associated with disease activity/duration/health status, physical activity, fatigue, and depression.

Acknowledgements: Supported by AZV-16-33574A, MHCR 023728.

Disclosure of Interests: Barbora Heřmánková: None declared, Maja Špiritović: None declared, Hana Smucrova: None declared, Sabina Oreska: None declared, Hana Štorkánová: None declared, Kristyna Bubova: None declared, Karel Pavelka: None declared, Jiř́ Vencovský Consultant for: Samsung, Speakers bureau: AbbVie, Novartis, Pfizer, Sanofi, Eli Lilly, Biogen, UCB, MSD, Werfen, Roche, Ladislav Šenolt Grant/research support from: AbbVie, Consultant for: AbbVie, Bristol-Myers Squibb, Celgene Corporation, Merck Sharp and Dohme, Novartis, Pfizer, Roche, UCB, Amgen, Takeda, Speakers bureau: AbbVie, Amgen, Bristol-Myers Squibb, Celgene Corporation, Eli Lilly, Merck Sharp and Dohme, Novartis, Pfizer, Roche, UCB, Radim Bečvář Consultant for: consultancy Actelion, Michal Tomčík: None declared

DOI: 10.1136/annrheumdis-2019-eular.4979

\section{SAT0259 $\quad$ PREDICTIVE FACTORS FOR TREATMENT RELATED MORTALITY AND MAJOR ADVERSE EVENTS AFTER AUTOLOGOUS HEMATOPOIETIC STEM CELL TRANSPLANTATION FOR SYSTEMIC SCLEROSIS: RESULTS OF A LONG TERM FOLLOW-UP MULTI- CENTRE STUDY}

Sandra van Bijnen ${ }^{1}$, Maaike Boonstra ${ }^{2}$, Cornelia van den Enden ${ }^{1}$, Julia Spierings ${ }^{3}$ Anne Schouffoer ${ }^{2}$, Jacob M. van Laar ${ }^{3}$, Thomas Huizinga ${ }^{2}$, Alexandre Voskuyl ${ }^{4}$, Walter van der Velden ${ }^{5}$, Frank van den Hoogen ${ }^{1}$, Jeska de Vries ${ }^{2}$, Madelon Vonk ${ }^{1}$. ${ }^{1}$ Radboud University Medical Center, Rheumatic diseases, Nijmegen, Netherlands ${ }^{2}$ Leiden University Medical Center (LUMC), Rheumatology, Leiden, Netherlands; ${ }^{3}$ University Medical Center Utrecht, Rheumatology, Utrecht, Netherlands; ${ }^{4}$ VUmc, Rheumatology, Amsterdam, Netherlands; ${ }^{5}$ Radboud University Medical Center, Hematology, Nijmegen, Netherlands

Background: Autologous hematopoietic stem cell transplantation (HSCT) has shown superior efficacy to cyclophosphamide pulse therapy in systemic sclerosis (SSc) but its application is hampered by high treatment related mortality (TRM). To date factors, other than smoking, predicting TRM are unknown.

Objectives: To describe event-free survival and TRM after HSCT and to evaluate the predictive value of baseline characteristics. Event-free survival was defined as the absence of mortality or major organ failure (i.e. cardiac failure (left ventricular ejection fraction (LVEF) $<30 \%$, respiratory failure (resting $\mathrm{PaO} 2<8 \mathrm{kPa} / 60 \mathrm{~mm} \mathrm{Hg}$ or $\mathrm{PaCO} 2>6,7 \mathrm{kPa}$ or chronic oxygen supplementation), or renal failure requiring dialysis.

Methods: All patients who started with the procedure of HSCT for SSC in the Netherlands between 1.1.1998 and 31.12.2016 were included. Except in 4 patients, eligibility criteria and procedures of the ASTIS trial were used (1). A Kaplan-Meier event-free survival curve was constructed. All deceased patients were discussed in a consensus meeting, to determine the cause of death as TRM, progression of SSc or other. The univariate association of TRM and event-free survival with baseline characteristics (gender, age, disease duration, smoking ever, FVC, DLCO, LVEF) was examined by Cox regression analysis.

Results: 92 patients were included, including 4 patients with limited cutaneous subtype who were treated because of interstitial lung disease. The median (IQR) follow-up time was 4.5 (2.3 - 12.3) years. Twenty patients died during the observation period of whom $10(10.8 \%, 9$ males) in the first year because of TRM. Twelve patients (13.1\%) developed major organ failure (6 lung, 3 kidney and 3 heart) of whom 8 died during the

Table 1:. demographic and disease related factors

\begin{tabular}{lc}
\hline Male/female & $49 / 43$ \\
\hline LcSSc/DcSSc & $4 / 88$ \\
Age at HSCT mean (SD) (year) & $46.8(10.3)$ \\
Disease duration at HSCT mean (SD)(year) & $2.4(2.4)$ median 1.6 \\
mRSS mean (SD) & $26(10.1)$ \\
Antibodies: ANA, ATA, Anti-RNAP positive & $88 / 92 ; 34 / 92 ; 1 / 92$ \\
Ever smoker & $54 / 84$ \\
FVC as\% pred. mean (SD) & $84.9(22.7)$ \\
DLCO as\% pred mean (SD) & $55.1(16.2)$ \\
LVEF $<50 \%$ (by echo) & $3 / 92$
\end{tabular}

observation period. Event-free survival after five and ten years was 68\% (40/59 patients) and 59\% (30/51), respectively. TRM was significantly associated with male gender (HR $(95 \% \mathrm{Cl})$ : $8.7(1.1-68.9)$, but not with smoking; events were associated with male gender, older age and LVEF $<50 \%$ at baseline (HR: $4.08(1.5-11.0) ; 1.1(1.0-1.1)$ and 4.7 (1.1 20.6), respectively).

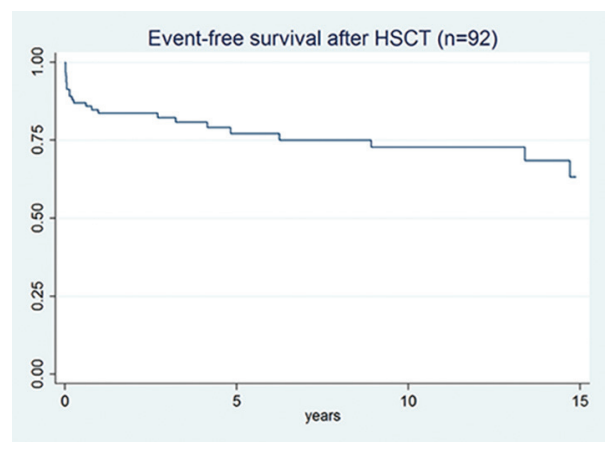

Conclusion: In this national cohort study of HCST in patients with SSC and poor prognosis we observed a median event-free survival of 4.3 years. TRM was $10,8 \%$ and major events occurred in 13\%. TRM was correlated to male gender. Low LVEF, male gender and older age were correlated with major events.

\section{REFERENCES}

[1] van Laar JM, Farge D, Sont JK, et al. Autologous hematopoietic stem cell transplantation vs intravenous pulse cyclophosphamide in diffuse cutaneous systemic sclerosis: a randomized clinical trial. JAMA. 2014;311 (24):2490-8.

Disclosure of Interests: Sandra van Bijnen: None declared, Maaike Boonstra: None declared, Cornelia van den Enden: None declared, Julia Spierings Grant/research support from: Boehringer Ingelheim, Anne Schouffoer: None declared, Jacob M. van Laar Grant/research support from: Genentech, Consultant for: F. Hoffmann-La Roche, Thomas Huizinga Consultant for: Merck, UCB, Bristol Myers Squibb, Biotest AG, Pfizer, GSK, Novartis, Roche, Sanofi-Aventis, Abbott, Crescendo Bioscience Inc., Nycomed Boeringher, Takeda, Zydus, Epirus, Eli Lilly, Alexandre Voskuyl: None declared, Walter van der Velden: None declared, Frank van den Hoogen: None declared, Jeska de Vries: None declared, Madelon Vonk Grant/ research support from: Madelon Vonk has received unrestricted research funds from Actelion and Therabel, Consultant for: Madelon Vonk was a consultant for Actelion, Boehringer-Ingelheim, Speakers bureau: Actelion, Boehringer-Ingelheim, Roche

DOI: 10.1136/annrheumdis-2019-eular.5380

\section{SAT0260 MUSCULAR INVOLVEMENT OF THE LOWER LIMBS IN PATIENTS WITH IDIOPATHIC INFLAMMATORY MYOPATHIES: A MRI EVALUATION}

Simone Barsotti ${ }^{1}$, Barbara Mugellini ${ }^{2}$, Alessandra Tripoli ${ }^{1}$, Giacomo Aringhieri ${ }^{2}$ Chiara Cardelli ${ }^{1}$, Elisa Cioffi ${ }^{1}$, Virna Zampa ${ }^{2}$, Davide Caramella ${ }^{2}$, Marta Mosca ${ }^{1}$, Rossella Neri ${ }^{1} .{ }^{1}$ University of Pisa, Rheumatology Unit, Pisa, Italy; ${ }^{2}$ University of Pisa, I radiology Unit, Pisa, Italy

Background: Since many years, muscular magnetic resonance imaging (MRI) has been used in the diagnosis and follow-up of patients with idiopathic inflammatory myopathies (IIM), but the clinical significance and the pattern of the muscular alterations (edema, fatty infiltration and atrophy) in different subsets of the disease are still not well defined.

Objectives: The aims of this study were to analyse possible differences in the involved muscles between dermatomyositis (DM) and polymyositis (PM); the correlations between the pattern of muscular involvement in dif ferent subsets of the disease and disease parameters in a monocentric cohort of patients.

Methods: We retrospectively collected data from 85 patients with poly and dermatomyositis (EULAR/ACR criteria) who performed pelvic and tights muscle MRI from January 2010 to December 2018: 27 had DM and $58 \mathrm{PM}$, mean age $58.6 \pm 13.4$ years, mean disease duration of $45 \pm 73$ months. The images in 22 muscles for the presence of muscular edema, fatty infiltrates and atrophy were assessed by a dedicated radiologist. Moreover, data about serum creatine kinase (CK) and manual muscle 